\title{
Simulasi Sinkronisasi Carrier pada Modulasi Digital menggunakan Matlab
}

\author{
DWI ARYANTA, ARSYAD RAMADHAN DARLIS, WI RDA SRI FARHANI \\ J urusan Teknik Elektro I nstitut Teknologi Nasional Bandung
}

Email: dwiaryanta@gmail.com

\begin{abstract}
ABSTRAK
Dalam sistem komunikasi digital, salah satu manfaat teknik pengkodean adalah sebagai efisiensi bandwidth. Pada kanal komunikasi, adanya noise akan mengganggu dan menurunkan kinerja sistem komunikasi digital. Hal ini menyebabkan terjadinya kesalahan pendeteksian sinyal pembawa, yang mengakibatkan terjadi perubahan bit atau simbol pada sisi penerima. Untuk mengurangi kesalahan deteksi, maka dibutuhkan suatu mekanisme sinkronisasi carrier di sisi penerima untuk mendapatkan data yang serupa dengan data yang dikirim. Simulasi sinkronisasi carrier pada penelitian ini menggunakan metode carrier phase recovery pada modulasi digital M-PSK dan M-QAM dengan level modulasi 4 sampai dengan 32, menggunakan software Matlab versi 7.9. Hasil pengujian sistem yang telah dilakukan pada Eb/No dengan rentang 0 hingga 30 dB menunjukkan, adanya peningkatan kinerja sistem pada modulasi M-PSK dari 0,01352 sampai dengan 0,8546, dan pada modulasi M-QAM dari 0,0256 sampai dengan 0,7867 .
\end{abstract}

Kata Kunci : M-PSK, M-QAM, Kanal AWGN, BER, Eb/No, Phase Recovery

\section{ABSTRACT}

The digital communication systems, one of the benefits coding techniques are as bandwidth efficiency. The communication channel, the presence of noise will disrupt and degrade the performance of digital communication systems. This leads to error detection of the carrier, resulting in a change of bits or symbols at the receiver side. To reduce the detection error, there is a need carrier synchronization at the receiver side to obtain similar data with the data sent. Simulation of carrier synchronization in this study using the carrier phase recovery method in digital modulation M-PSK and M-QAM modulation with levels 4 to 32, using Matlab software version 7.9. The results of system testing has been done on the $E b$ / No ranging from 0 to $30 \mathrm{~dB}$ shows, an increase in the performance of the system on the M-PSK modulation from 0.01352 to 0.8546 , and the M-QAM modulation from 0.0256 to $0,7867$.

Keywords: M-PSK, M-QAM, AWGN Channel, BER, Eb/No, Phase Recovery 


\section{PENDAHULUAN}

Pada sistem komunikasi analog maupun digital, semua informasi akan ditransmisikan melalui suatu medium yang memisahkan antara pengirim dan penerima. Agar data yang dikirim sesuai dengan yang diterima, maka dibutuhkan sinkronisasi carrier pada proses modulasi. Terjadinya sinkronisasi menyimpang ini akibat adanya noise yang di dalamnya terjadi perubahan fasa sehingga data yang diterima sudah tidak sesuai dengan yang dikirim.

Adapun beberapa penelitian yang telah dilakukan diantaranya yang pertama adalah dengan melakukan visualisasi yang dapat menggambarkan proses kinerja sistem 16-QAM secara sederhana, sehingga mempermudah memahami proses kerja dari pengiriman dan penerimaan pada teknik modulasi 16-QAM. Visualisasi sistem 16-QAM dibuat bahasa pemograman JAVA sehingga dapat menampilkan sinyal hasil proses pengiriman dan penerimaan dari sistem 16-QAM. (Aditya, 2010)

Selanjutnya penelitian yang kedua dengan melakukan pengamatan BER (Bit Error Rate) sebagai fungsi SNR (Signal to Noise Ratio) untuk kinerja sistem Multicarrier Code Division Multiple Access (MC-CDMA) Multiuser Detection Parallel Interference Cancellation (MUD PIC). Modulasi yang digunakan adalah M-QAM untuk jumlah user tertentu di lingkungan yang dipengaruhi kanal AWGN dan Rayleigh fading. PN-Code yang digunakan adalah Gold Code 31 , maksimum user adalah 25, subcarrier yang digunakan adalah 7,31 dan 63. Jumlah maksimum stage adalah 3. (Dwi Darmi, 2011)

Dan yang ketiga adalah penelitian dengan melakukan pearancangan perangkat demodulator 16-QAM menggunakan matlab simulink yang kemudian diimplementasikan pada DSK TMS320C6713 dengan bantuan fitur Target for TIC6000. Demodulator ini bertujuan untuk menerima data berupa sinyal termodulasi dari pengirim yang akan didemodulasikan kembali menjadi sinyal informasi yang sesuai dengan pengirim. Sinyal keluaran dari demodulator yang dibangun pada DSK disalurkan melalui Real-Time data Exchange (RTDX). (Ananta, 2008)

Penggunaan teknik Costas Loop untuk sinkronisasi fasa pada modulasi BPSK (Binery Phase Shift Keying) dan seberapa jauh efek sinkronisasi yang tidak sempurna pada kinerja sistem BPSK. Penelitian ini disajikan untuk melakukan evaluasi terhadap modul tutorial yang disajikan dalam proses perkuliahan. Selanjutnya dilakukan evaluasi dengan pengambilan data melalui quisioner. Dari data yang terkumpul didapatkan hasil bahwa modul tutorial ini belum banyak membantu mahasiswa dalam pemahaman konsep sinkronisasi.(Harsono, 2009)

Sesuai dengan perkembangannya, maka dilakukanlah penelitian lebih lanjut mengenai "Simulasi Sinkronisasi Carrier Pada Modulasi Digital Dengan Menggunakan Matlab Versi 7.9." yang bertujuan untuk mensinkronkan antara data yang dikirim dengan data yang diterima. Dengan menggunakan modulasi digital berupa M-PSK dan M-QAM, serta menjadikan diagram konstelasi dan garfik BER sebagai output pada simulasi. Dan pada proses komunikasi menggunakan kanal AWGN sebagai penghubung antara pengirim dan penerima. 


\section{METODOLOGI}

\subsection{Perancangan Sistem}

Pada bab ini akan dibahas mengenai langkah - langkah yang dilakukan untuk merancang simulasi sinkronisasi carrier menggunakan modulasi digital, yang meliputi input data yang dikirim sampai dengan output data yang diterima serta proses yang terjadi di dalamnya. Adapun blok diagram dari penelitian ini seperti pada Gambar 1.

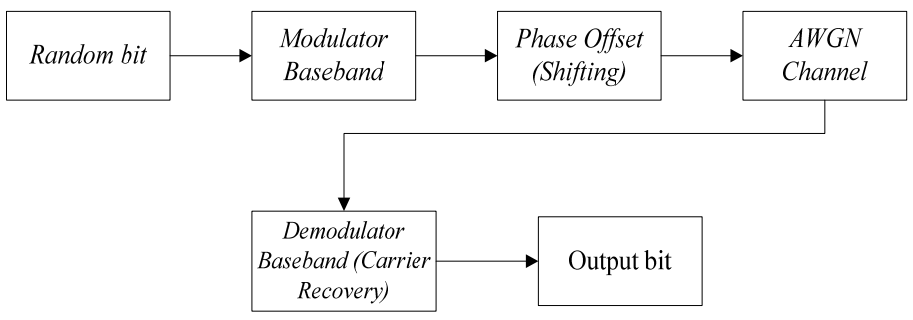

\section{Gambar 1. Blok diagram sinkronisasi carrier pada modulasi digital}

Adapun flowchart perancangan simulasi sinkronisasi carrier pada komunikasi digital dapat dilihat pada Gambar 2.

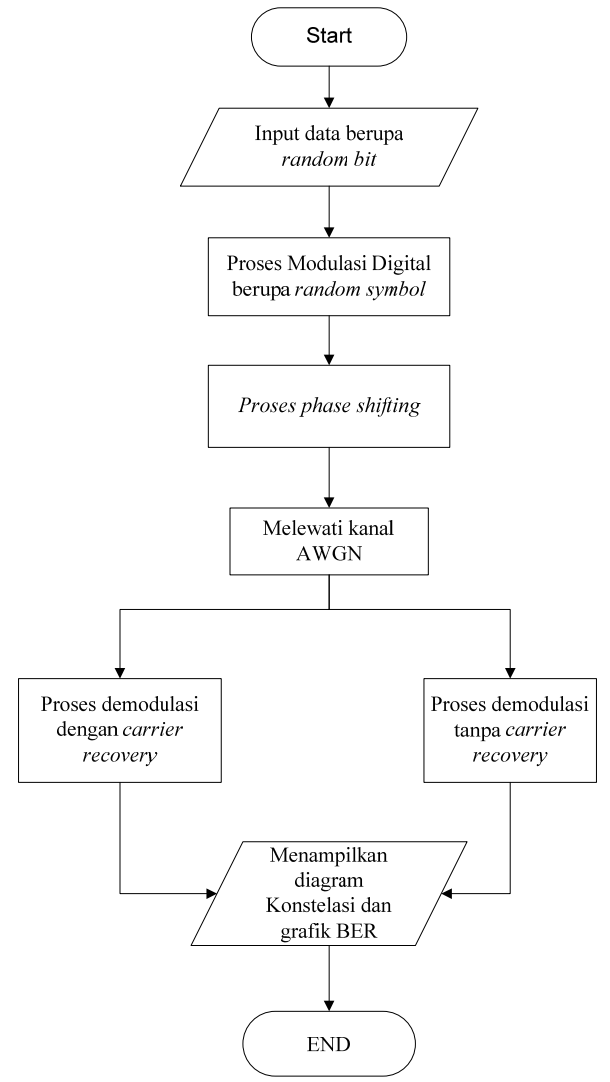

Gambar 2. Flowchart simulasi sinkronisasi carrier pada modulasi digital 
Berdasarkan blok diagram sebelumnya pada Gambar 1, yang diperjelas dengan tampilan flowchart pada Gambar 2 untuk sistem kinerja sinkronisasi carrier pada modulasi M - PSK dan M - QAM dengan level modulasi 4, 8, 16 dan 32, secara umum langkah - langkah simulasi pada penelitian ini adalah sebagai berikut :

1. Input data random bit

Pada sisi receiver, yang akan dijadikan sebagai input berupa sinyal diskrit secara acak, baik input untuk modulasi M-PSK dan M-QAM. Hal ini bertujuan untuk mempermudah modifikasi sinyal dalam proses simulasi dalam penggunaan software matlab. Jumlah bit yang dibangkitkan dapat disesuaikan. Namun pada simulasi ini akan dibangkitkan sinyal sebanyak 30000 bit. Seperti yang tertera pada syntax berikut ini.

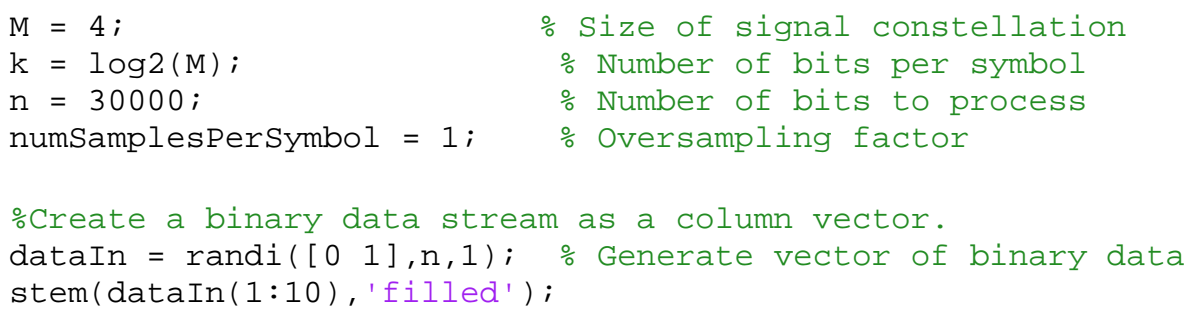

Jika dilihat pada syntax diatas, dengan menggunakan level modulasi $(\mathrm{M})=4$, maka input akan dibangkitkan secara acak sebanyak 30000 bit. Nilai dari M dapat diganti sesuai dengan level modulasi yang digunakan. Dengan jumlah sample per symbol $=1$. Namun data yang ditampilkan hanya berjumlah 10 bit pertama agar sinyal yang ditampilkan terlihat jelas dan beraturan.

2. Proses Modulasi

Pada proses modulasi, karena input yang dikirim berupa sinyal diskrit, maka hasil dari proses modulasi juga berupa sinyal diskrit, sesuai dengan modulasi yang digunakan pada M-PSK dan M-QAM. Pada proses modulasi ini, data yang akan dibangkitkan berupa bit simbol secara acak. Data input yang masuk secara biner, akan diubah menjadi bentuk desimal.

\% Modulator object

pskmodObj $=\operatorname{modem} \cdot \operatorname{pskmod}(M)$;

pskSym $=\operatorname{modulate}(\operatorname{modem} . \operatorname{pskmod}(M), r \times D a t a)$;

Berdasarkan syntax diatas, modulasi yang digunakan adalah PSK. Dan jika ingin menggunakan modulasi QAM, cukup dengan menggantinya dengan modem.qammod, dan level modulasi (M) yang akan digunakan. Serta mengganti syntax PSK dengan QAM.

\section{Proses Phase Shifting}

Setelah melewati proses modulasi, maka sinyal akan diberikan pergeseran fasa (phase shifting) dari $0^{\circ}$ menjadi $15^{\circ}, 30^{\circ}$, dan $45^{\circ}$. Dengan memberikan sedikit modifikasi terhadap perubahan fasa, maka fasa yang bergeser akan dilakukan sinkronisasi dari pengirim terhadap penerima. Jika pada modulasi digital yang digunakan PSK dan QAM, maka fasa sangat berpengaruh terhadap jalannya proses demodulasi

$$
\mathrm{y} 1=\operatorname{pskmod}(\mathrm{x}, 4,0) ; \quad \% \text { 4-PSK output, phase offset }=0
$$


Dengan menggunakan perintah diatas, maka fasa yang awlanya bernilai $0^{\circ}$, maka akan dilakukan perubahan sebesar $15^{\circ}, 30^{\circ}$, dan $45^{\circ}$ dari setiap modulasi yang digunakan. Dimana hasil dari pergeseran fasa ini berupa diagram konstelasi dan grafik BER.

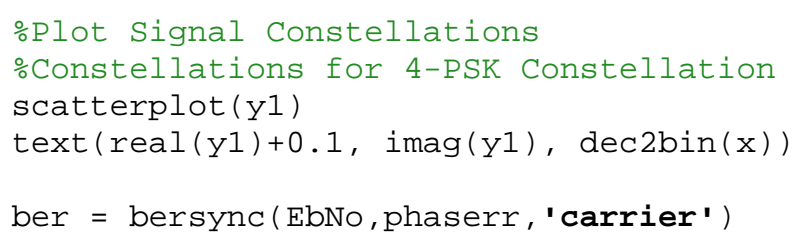

4. Melewati kanal AWGN (Additive White Gaussian Noise)

Setelah melewati proses pergeseran fasa, maka sinyal akan melewati kanal AWGN. Dimana di dalam kanal tersebut terdapat noise yang dapat merusak bentuk asli dari sinyal. Dengan demikian, tampilan diagram konstelasi dan grafik BER yang dipengaruhi kanal AWGN akan menghasilkan fasa yang telah bergeser dari bentuk semula dan ditambah dengan noise. Maka diagram konstelasi akan terdistribusi dari keadaan semula melalui proses pada syntax berikut.

\%the AWGN channel.

EbNo = 10;

$\mathrm{snr}=\mathrm{EbNo}+10 * \log 10(\mathrm{k})-10 * \log 10($ numSamplesPerSymbol $) ;$

receivedSignal $=\operatorname{awgn}($ dataMod, snr, 'measured');

5. Demodulasi tanpa Carrier Recovery

Pada proses demodulasi sebelum dilakukannya carrier recovery (perbaikan fasa), maka sinyal yang diterima pada sisi receiver tidak sesuai dengan sinyal yang dikirim. Maka disini tidak terjadi proses sinkronisasi antara sinyal pengirim dengan sinyal penerima. Dengan menampilkan output berupa diagram konstelasi dan grafik BER, akan terlihat hasil demodulasi tanpa perbaikan fasa (carrier recovery) berbeda dengan data awalnya.

6. Demodulasi dengan Carrier Recovery

Pada penelitian ini akan menjadikan fasa sebagai target noisenya, maka dilakukanlah phase recovery, yaitu perbaikan fasa yang terjadi akibat perubahan fasa pengirim dan penerima. Maka dibutuhkan sebuah proses untuk mensinkronkan sinyal carrier dengan menggunakan metode Costas Loop. Mekanisme kinerja costas loop akan mencari kesalahan fasa minimum. Sehingga sinyal carrier yang dibangkitkan oleh costas loop akan menghasilkan sinyal yang serupa dengan yang dikirim. Dan pada sisi penerima, akan menerima sinyal sesuai dengan sinyal yang dikirimkan oleh transmitter.

hDemod $=$ modem. pskdemod $(M)$;

zsym = demodulate (hDemod, ynoisy);

rxSamples $\odot=$ downsample (rxSamples, eq0bj.nSampPersym);

\% Payload samples

yPayloade $=$ rxSamples $\odot($ nTrain $+(1:$ nPayload $)) ;$

$[\sim$, BER $\odot$, yErro $]=$ commadapteq_pskdetect $(\ldots$

yPayloado, xPayload, payloadData, M);

7. Menampilkan diagram Konstelasi dan grafik BER.

Pada simulasi ini, diagram konstelasi akan dibangkitkan sebanyak tiga kali yaitu ketika hasil modulasi, hasil pergeseran fasa (phase offset) dan setelah melewati kanal AWGN. Setiap diagram konstelasi mewakili setiap proses yang terjadi. Dan untuk output terakhir akan ditampilkan grafik BER. Dimana BER juga akan menampilkan hasil dari pergeseran fasa dan setelah terjadinya sinkronisasi dari sinyal pembawa. 


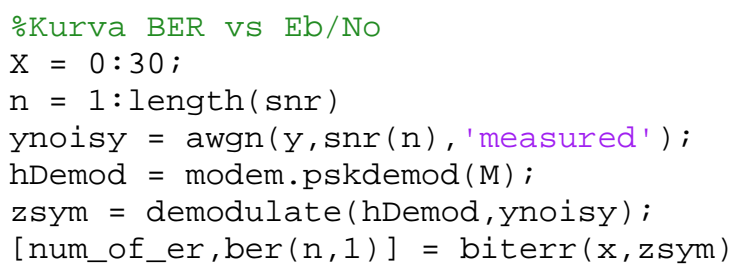

Tampilan diagram konstelasi dan grafik BER merupakan output setiap proses yang telah dilewati, baik saat mengalami pergeseran fasa maupun setelah perbaikan fasa.

\section{PENGUJ I AN DAN ANALISIS}

Pada bab ini dilakukan pengujian sistem secara keseluruhan, dimana akan diuji mulai dari data input dan data output serta sinkronisasi yang terjadi pada masing - masing modulasi digital M-PSK dan M-QAM. Adapun masing-masing pengujian tersebut memiliki penjelasan sebagai berikut.

\subsection{Input Berupa Bit Acak}

Pada simulasi modulasi M-PSK dan M-QAM, input data digital akan dibangkitkan secara acak dalam bentuk sinyal diskrit. Hal ini bertujuan untuk mempermudah modifikasi sinyal dalam proses simulasi. Pada setiap modulasi, akan digunakan bermacam M diantaranya 4, 8, 16 dan 32. Jumlah sinyal informasi yang digunakan dalam simulasi ini adalah 30000 bit yang dibangkitkan secara acak. Pada Gambar 3 menampilkan 10 bit pertama dari sinyal informasi biner yang dibangkitkan.

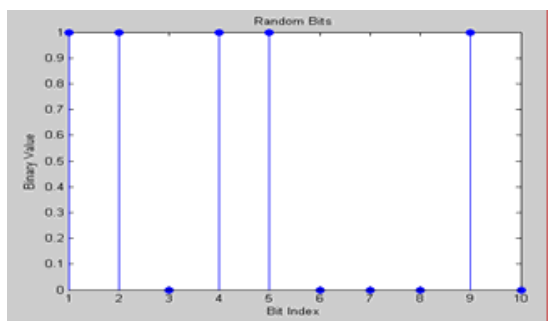

Gambar 3. Input bit acak

\subsection{Proses Modulasi}

Pada proses modulasi, data input diubah ke dalam bentuk simbol. Setiap input bit mewakili setiap simbol yang ditampilkan dan disusun secara acak. Gambar 4 menunjukkan hasil dari konversi input jika diubah ke dalam bentuk simbol dari QPSK dan QAM.

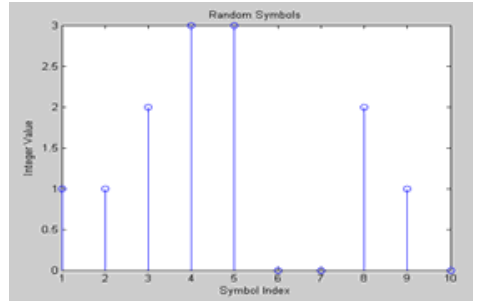

(a)

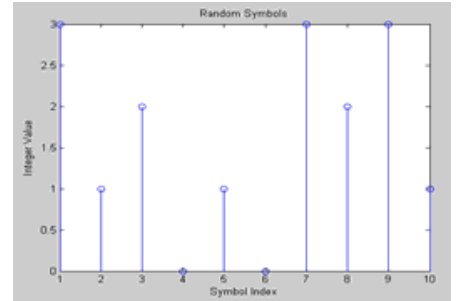

(b)

Gambar 4. (a) Hasil modulasi QPSK yang dikonversi kedalam bentuk simbol. (b) Hasil modulasi QAM yang dikonversi kedalam bentuk simbol. 
Hasil simulasi pada Gambar 4, mewakili dari setiap proses modulasi digital yang digunakan. Pada penggunaan modulasi QPSK dan QAM, maka amplitudo yang dibangkitkan akan bernilai 0 - 3 sebanyak bit yang dibangkitkan. Untuk penggunaan modulasi 8-PSK dan 8-QAM, maka nilai amplitudo yang dibangkitkan antara $0-7$. Pada penggunaan modulasi $16-P S K$ dan $16-$ QAM, maka amplitudo yang dibangkitkan akan bernilai 0 - 15 sebanyak bit yang dibangkitkan. Dan pada penggunaan modulasi 32-PSK dan 32-QAM, maka amplitudo yang dibangkitkan akan bernilai 0 - 31. Jadi, setiap simbol yang dihasilkan merepresentasikan data biner yang dikirimkan.

Setelah diubah ke dalam bentuk simbol, maka akan dilanjutkan pada tampilan diagram konstelasi untuk modulasi M-PSK dan M-QAM sebelum melewati kanal AWGN. Diagram ini dalam keadaan awal tanpa adanya perubahan phase offset, dalam artian CPO (Carrier Phase Offset $)=0$. Terlihat pada Tabel 1 di bawah ini.

Tabel 1 Diagram Konstelasi M-PSK dan M-QAM hasil modulasi

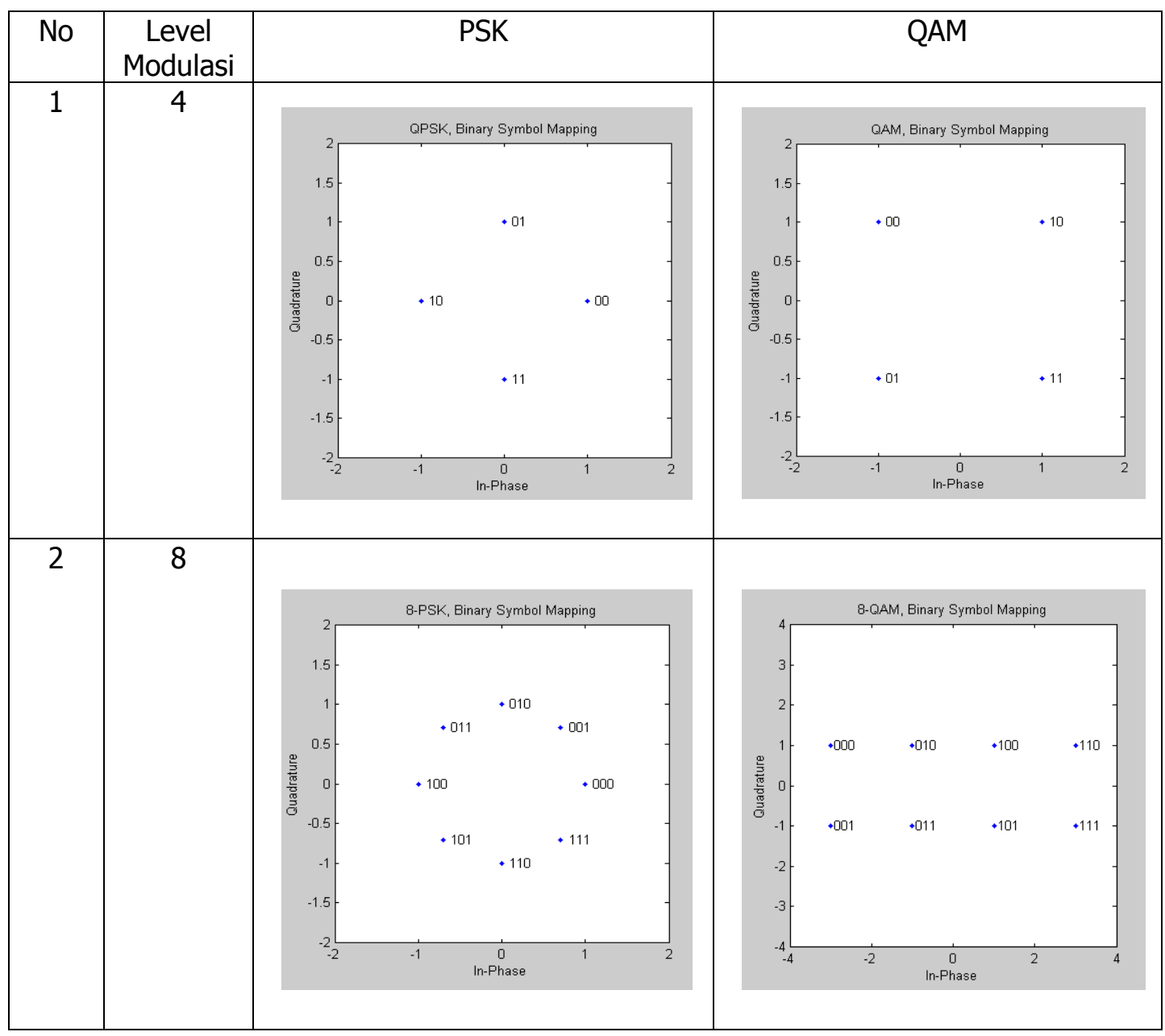


Tabel 1 Diagram Konstelasi M-PSK dan M-QAM hasil modulasi (lanjutan)

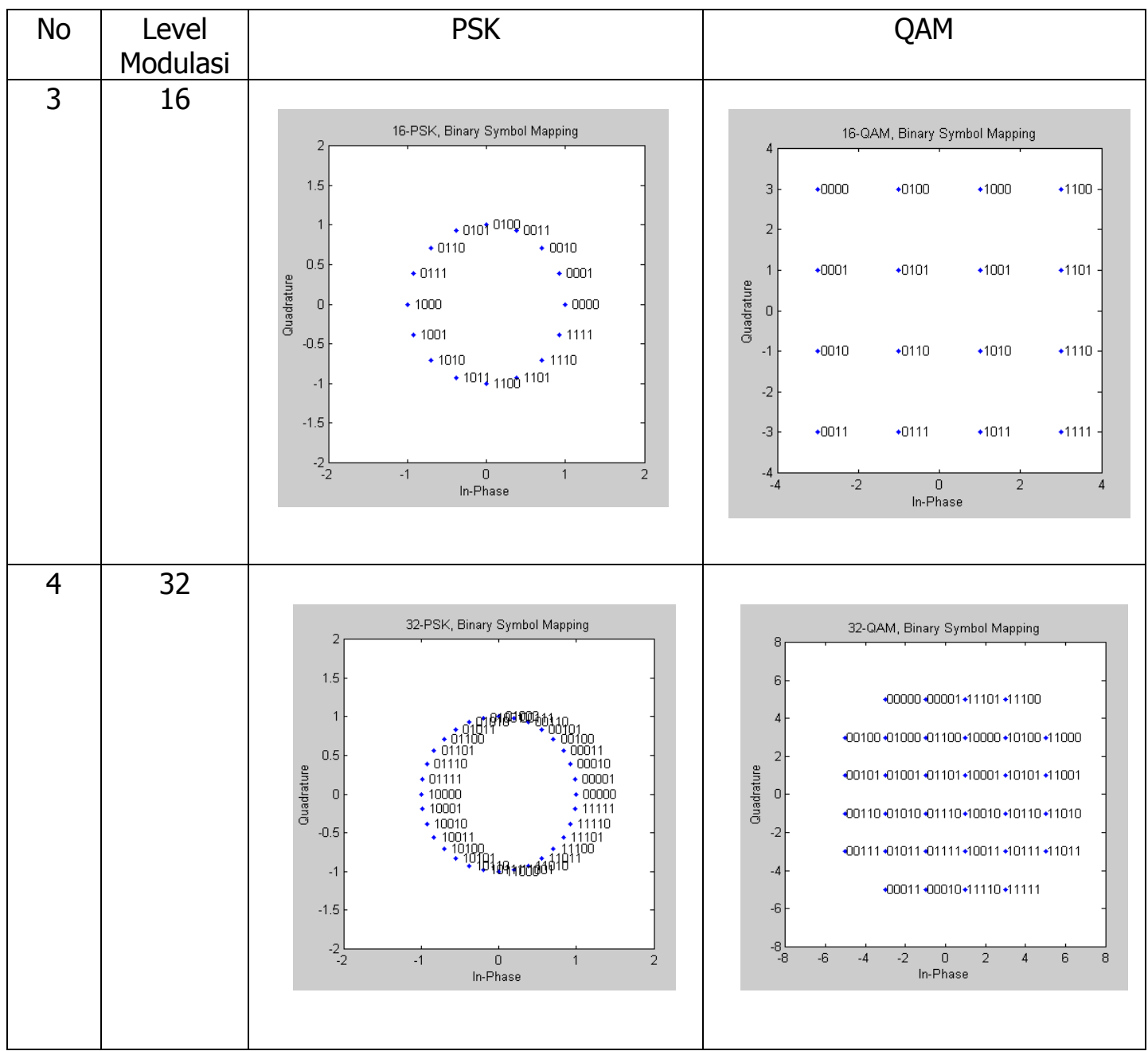

Dari hasil modulasi yang ditampilkan pada diagram konstelasi pada Tabel 1 , jika dianalisis pada hasil modulasi QPSK, berarti terdapat 1 dari 4 kemungkinan sinyal ditransmisikan setiap 1 interval pensinyalan, dimana setiap sinyal (simbol) terdiri dari 2 bit. Sebagai contoh terdapat 4 kemungkinan symbol yaitu 00,10,11, dan 01 direpresentasikan dengan mengirimkan sinyal pembawa sinusoidal dengan satu dari 4 kemungkinan nilai. Dengan jumlah amplitudo $=1$, dan jumlah fasa $=4$, yaitu pada $0^{\circ}, 90^{\circ}, 180^{\circ}$, dan $270^{\circ}$. Begitu juga dengan diagram konstelasi QAM, yang sama - sama memiliki perbedaan $90^{\circ}$ dari setiap jarak antar simbol yang berdekatan.

Untuk diagram konstelasi 8-PSK dan 8-QAM, berarti terdapat 1 dari 8 kemungkinan sinyal ditransmisikan setiap 1 interval pensinyalan, dimana setiap sinyal (simbol) terdiri dari 3 bit. Sebagai contoh terdapat 8 kemungkinan simbol yaitu 000, 001, 010, 011, 100, 101, 110, dan 110 direpresentasikan dengan mengirimkan sinyal pembawa sinusoidal dengan satu dari 8 kemungkinan nilai. Dengan jumlah amplitudo $=1$, dan jumlah fasa $=8$, yaitu pada $0^{\circ}, 45^{\circ}$, $90^{\circ}, 135^{\circ}, 180^{\circ}, 225^{\circ}, 270^{\circ}$ dan $315^{\circ}$. 


\subsection{Proses Melewati Kanal AWGN}

Proses selanjutnya, sinyal akan melewati kanal AWGN (Additive White Gaussian Noise) dan menghasilkan diagram konstelasi seperti pada Tabel 2. Dimana pada kanal AWGN terdapat karakter kanal yang akan mempengaruhi dari bentuk asli hasil diagram konstelasi.

Tabel 2. Diagram konstelasi M-PSK dan M-QAM setelah melewati kanal AWGN

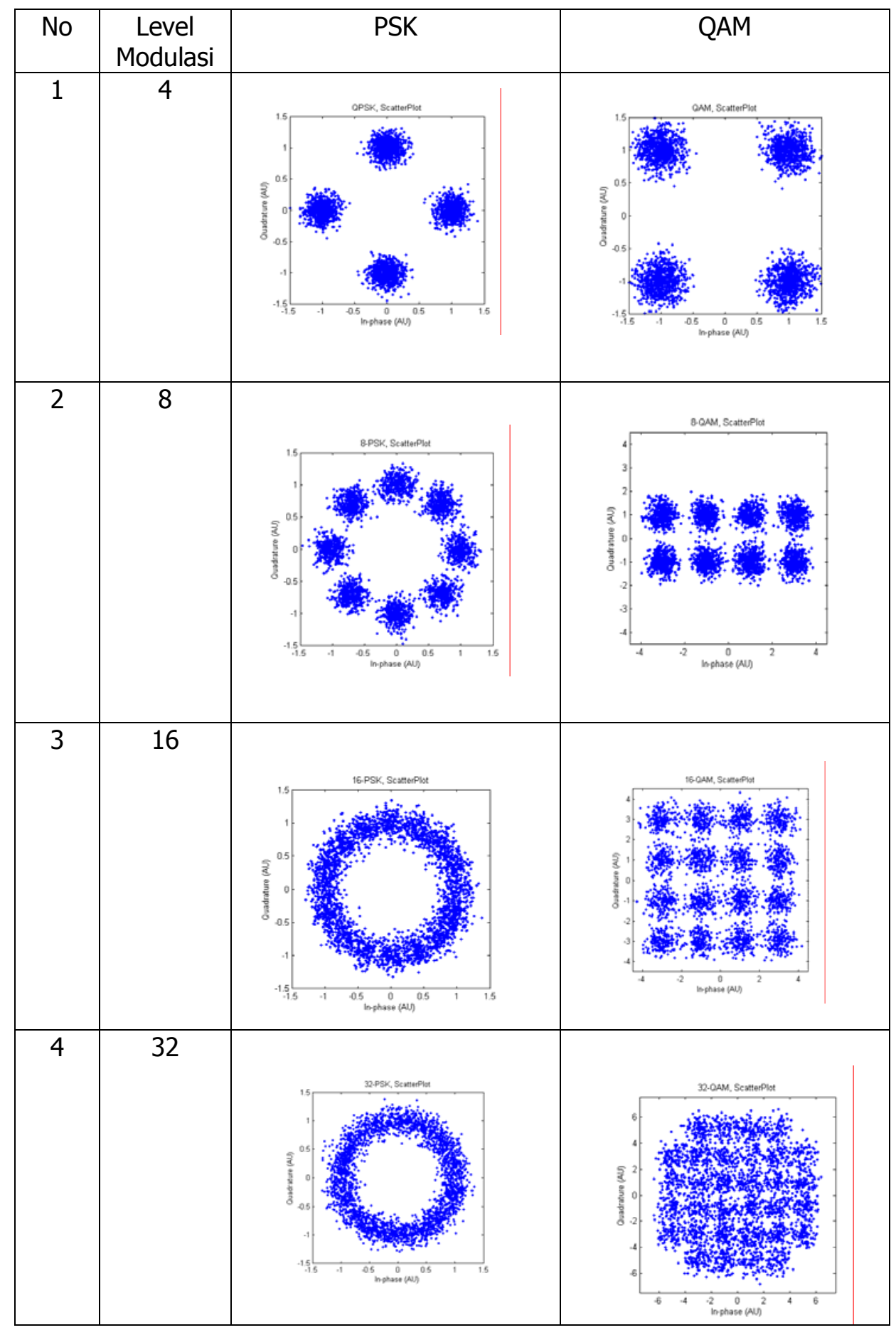


Dari hasil diagram konstelasi yang telah melewati kanal AWGN, dapat dianalisis bahwa setiap diagram konstelasi menjadi terdistribusi menyimpang dan tidak beruaturan disebabkan karena karakteristik dari kanal AWGN itu sendiri. Sehingga menyebabkan sinyal yang dikirim, tidak sama dengan sinyal yang diterima.

Disamping itu, jika diperhatikan setiap sinyal yang melewati kanal AWGN, semakin besar level modulasi, maka akan semakin rentan. Hal ini dibuktikan dari bit yang dibangkitkan sebanyak 30000, maka jika pada level modulasi $(M)=4$, berarti terdapat 4 simbol yang mempunyai 2 bit per simbol. Maka pada diagram konstelasi terdapat 15000 simbol yang tidak beraturan.

Begitu juga pada $M=8$, dimana terdapat 8 simbol dengan 3 bit mewakili setiap simbol. Maka pada diagram konstelasi akan menampilkan jumlah simbol sebanyak 10000 simbol secara acak dalam satu diagram konstelasi. Untuk $M=16$, maka terdapat 16 simbol dengan 4 bit mewakili setiap simbol. Berarti dalam satu diagram konstelasi akan menampilkan sebanyak 7500 simbol. Dan untuk $M=32$, dimana terdapat 32 simbol dengan 5 bit per simbol. Maka dalam satu diagram konstelasi akan menampilkan 6000 simbol. Dengan demikian, dapat dianalisis bahwa semakin tinggi level modulasi (M), maka jumlah simbol yang dibangkitkan akan semakin menurun, namun antar simbol lebih rentan terinteferensi terhadap simbol yang berdekatan.

\subsection{Proses Phase Shifting}

Setelah proses melewati kanal AWGN, maka dilanjutkan dengan pergeseran fasa sebesar $15^{\circ}, 30^{\circ}$, dan $45^{\circ}$. Pergeseran fasa ini dilakukan untuk mengamati perubahan sinyal yang diterima pada sisi receiver. Karena pada penelitian ini akan mengamati sinkronisari carrier, maka disini yang menjadi targetnya adalah fasa. Oleh karena itu, dilakukanlah modifikasi pada fasa setiap modulasi.

Pada diagram konstelasi hasil pergeseran fasa, dapat dianalisis bahwa setiap perubahan fasa, posisi sinyal berubah dari bentuk semula. Semakin besar fasa yang diberikan, maka sinyal juga akan semakin menjauhi posisi semula. Namun yang tidak berubah adalah amplitudo karena pada proses ini amplitudo bersifat konstan. Maka dibutuhkan sebuah sinkronisasi antara data pengirim dan penerima.

\subsection{Menampilkan Grafik BER hasil Phase Shifting}

Setelah menampilkan diagram konstelasi, maka dilihat juga perubahan pada grafik BER dengan perubahan fasa sebesar $15^{\circ}, 30^{\circ}$ dan $45^{\circ}$. Dengan ditampilkannya pada grafik BER, maka akan terlihat jelas perbedaan kinerja setiap modulasi ketika diberikan perubahan fasa. Hal terlihat pada Tabel 3 seperti dibawah ini.

Tabel 3. Grafik BER dengan pergeseran fasa pada M-PSK dan M-QAM

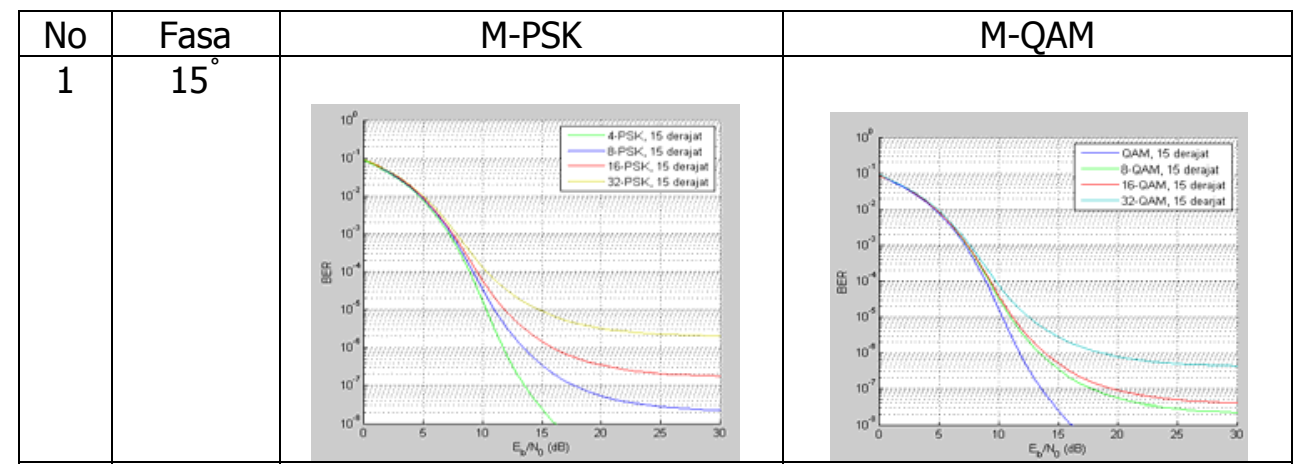


Tabel 3. Grafik BER dengan pergeseran fasa pada M-PSK dan M-QAM (lannjutan)

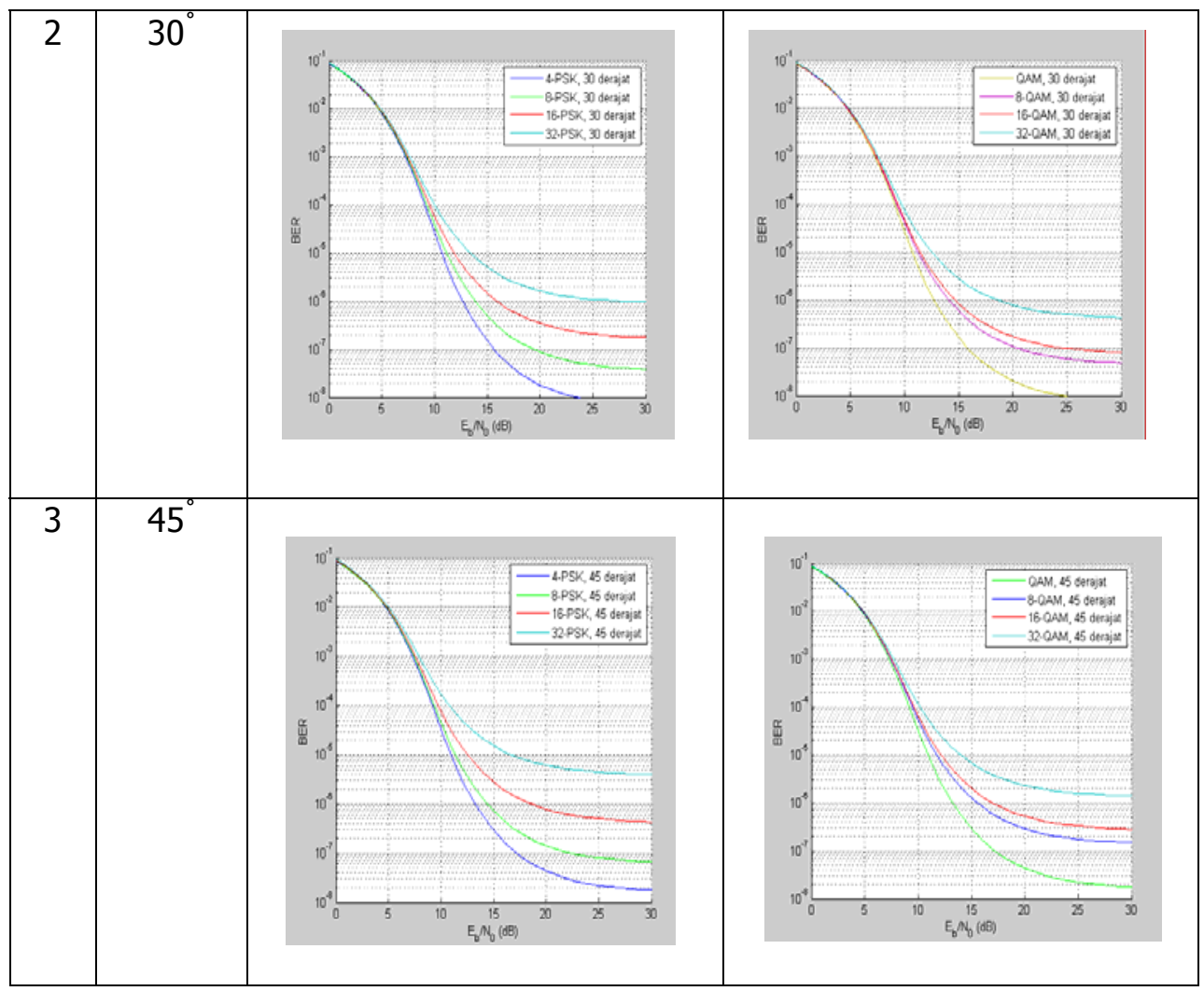

Berdasarkan hasil tampilan grafik BER yang telah diberikan perubahan fasa, maka tampak bahwa kinerja sistem menunjukkan nilai BER yang hampir sama. Karena pada dasarnya QPSK dan QAM memiliki diagram konstelasi yang sama karena kedua modulasi tersebut memiliki simbol dengan beda fasa yang sama untuk tiap simbol dimana masing-masing simbol memiliki beda fasa $90^{\circ}$. Walaupun diberikan pergeseran fasa yang sama, terlihat pada kedua modulasi bahwa semakin kecil jumlah $\mathrm{M}$ nya, maka akan semakin mendekati kondisi semula. Begitu jga sebaliknya, semakin besar jumlah $M$ yang dimiliki suatu modulasi, maka akan memiliki pergeseran fasa yang signifikan dari kondisi awal. Hal ini disebabkan karena terjadinya ketidaksinkronan carrier yang mengakibatkan data yang dikirim terdistribusi. Dampak dari kondisi ini menyebabkan grafik BER yang berbeda dari kondisi ideal.

Dari grafik kinerja BER, dapat disimpulkan semakin besar pergeseran fasa maka kinerja akan mengalami penurunan. Sebagai contoh modulasi QPSK pada pergeseran fasa sebesar $15^{\circ}$ terhadap Eb/No $15 \mathrm{~dB}$ bernilai $0,3.10^{-8}$, untuk pergeseran fasa $30^{\circ}$ dengan Eb/No yang sama yaitu $15 \mathrm{~dB}$ bernilai $10^{-7}$. Dan pada $45^{\circ}$ bernilai $0.5 \cdot 10^{-7}$. Ini membuktikan bahwa semakin besar pergeseran fasa yang diberikan, maka kinerja BER akan menurun. Karakteristik dampak perubahan fasa juga terlihat pada modulasi lainnya (M-PSK dan M-QAM).

\subsection{Menampilkan Grafik BER Hasil Demodulasi dengan Carrier Recovery}

Dampak yang terjadinya akibat adanya Carrier Phase Offset (CPO) adalah semakin menurunnya kinerja penerima, maka diperlukan upaya untuk mensinkronkan kembali dengan menggunakan costast loop. Dimana costast loop berfungsi untuk menekan 
perbedaan fasa di sisi penerima. Hasil dari phase recovery dapat dilihat pada Tabel 4 grafik BER yang sudah dilakukan perbaikan fasa

Tabel 4. Perbandingan Grafik BER sebelum dan sesudah dilakukan perbaikan fasa pada MPSK

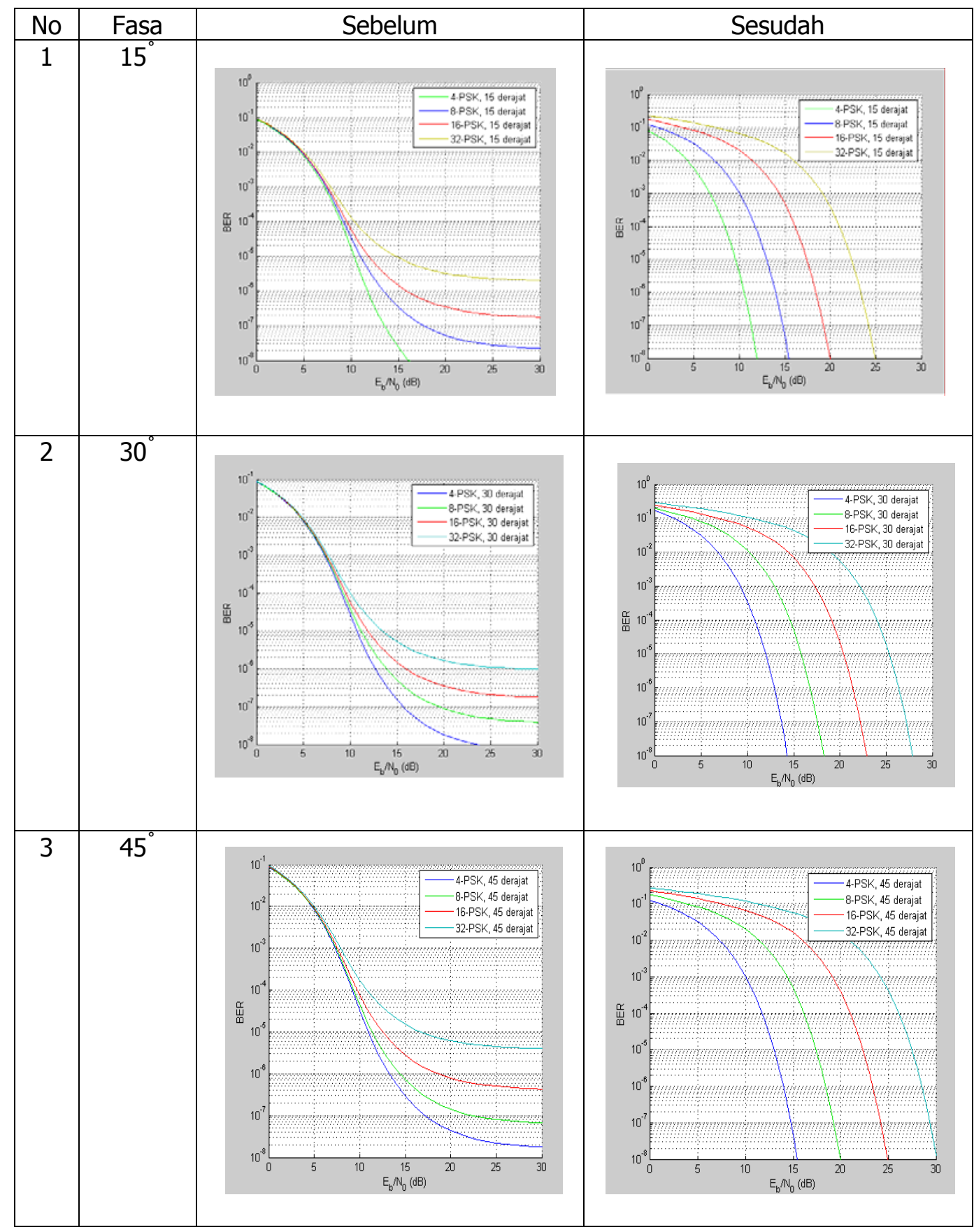


Tabel 5. Perbandingan Grafik BER sebelum dan sesudah dilakukan perbaikan fasa pada M-QAM

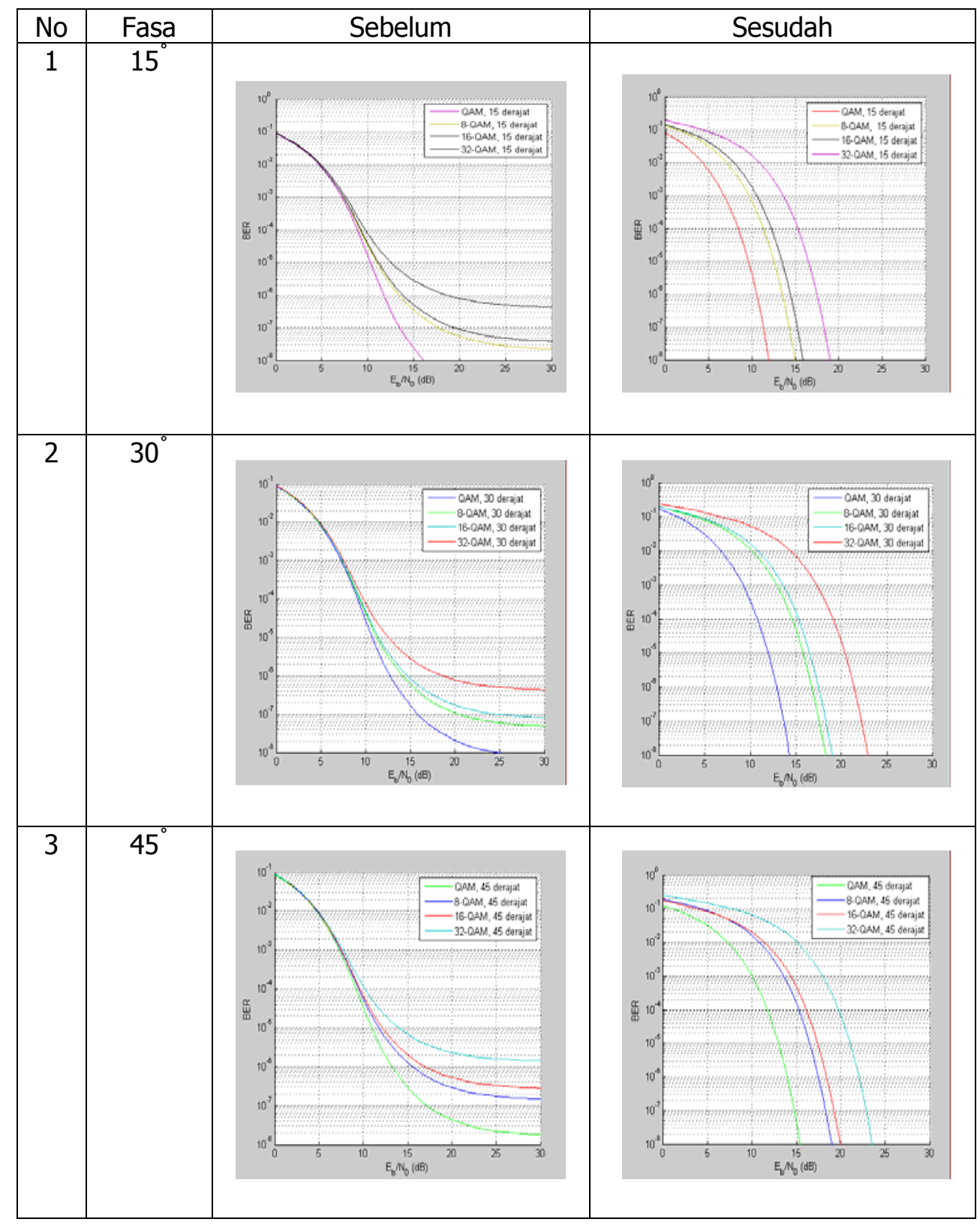

Berdasarkan dari grafik perbandingan hasil perbaikan fasa (phase recovery) dengan sebelum dilakukan perbaikan fasa, dapat dianalisis jika pada modulasi QPSK dengan titik pengamatan $\mathrm{Eb} /$ No $15 \mathrm{~dB}$, setelah dilakukan pergeseran fasa sebesar $15^{\circ}$ kinerja BER pada penerima bernilai $10^{-5}$, dan setelah dilakukan perbaikan sinyal pembawa kinerja BER menjadi $10^{-6}$. Ini membuktikan bahwa kinerja BER semakin membaik ketika setelah dilakukan perbaikan sinyal pembawa. Begitu juga seterusnya untuk lebih memperjelas kinerja BER maka dapat lihat pada Tabel 6 berikut. 
Tabel 6. Tabel hasil BER dari perbaikan fasa pada M-PSK dan M-QAM

\begin{tabular}{|c|c|c|c|}
\hline $\begin{array}{c}\text { Perubahan } \\
\text { Fasa (derajat) }\end{array}$ & Modulasi & $\Delta$ Min & $\Delta$ Max \\
\hline \multirow{2}{*}{15} & M-PSK & 0.01352 & 0.4746 \\
\cline { 2 - 4 } & M-QAM & 0.0256 & 0.5896 \\
\hline \multirow{2}{*}{30} & M-PSK & 0.03352 & 0.5546 \\
\cline { 2 - 4 } & M-QAM & 0.0476 & 0.7843 \\
\hline \multirow{2}{*}{45} & M-PSK & 0.06352 & 0.8546 \\
\cline { 2 - 4 } & M-QAM & 0.0765 & 0.7867 \\
\hline
\end{tabular}

Pada grafik BER hasil carrier recovery, terlihat perbedaan dari keadaan ideal bentuk grafik BER dari setiap modulasi. Setiap modulasi juga mempunyai trade off untuk memperoleh keadaan ideal BER tersebut. Pada pergeseran fasa $15^{\circ}$, hasil pengujian kinerja BER pada modulasi M-PSK sebelum dan sesudah dilakukannya phase recovery menunjukkan perbaikan BER sebesar 0,01352 sampai dengan 0,4746 pada rentang Eb/No hingga $30 \mathrm{~dB}$. Sedangkan pada modulasi M-QAM sebelum dan sesudah dilakukannya phase recovery menunjukkan perbaikan BER sebesar 0,0256 sampai dengan 0,5896 pada rentang Eb/No hingga $30 \mathrm{~dB}$.

Pada pergeseran fasa $30^{\circ}$, hasil pengujian kinerja BER pada modulasi M-PSK sebelum dan sesudah dilakukannya phase recovery menunjukkan perbaikan BER sebesar 0,03352 sampai dengan 0,5546 pada rentang Eb/No hingga $30 \mathrm{~dB}$. Sedangkan pada modulasi M-QAM sebelum dan sesudah dilakukannya phase recovery menunjukkan perbaikan BER sebesar 0,0476 sampai dengan 0,7843 pada rentang Eb/No hingga $30 \mathrm{~dB}$.

Pada pergeseran fasa $45^{\circ}$, hasil pengujian kinerja BER pada modulasi M-PSK sebelum dan sesudah dilakukannya phase recovery menunjukkan perbaikan BER sebesar 0,06352 sampai dengan 0,8546 pada rentang Eb/No hingga $30 \mathrm{~dB}$. Sedangkan pada modulasi M-QAM sebelum dan sesudah dilakukannya phase recovery menunjukkan perbaikan BER sebesar 0,0765 sampai dengan 0,7867 pada rentang Eb/No hingga $30 \mathrm{~dB}$.

Perbaikan kinerja BER pada simulasi yang dilakukan disebabkan karena proses awal carrier recovery adalah untuk mendapatkan simbol sinkronisasi sebelum pemulihan pembawa karena simbol fasa dapat ditentukan tanpa sepengetahuan dari fasa pembawa.

\section{KESI MPULAN}

Berdasarkan hasil dari implementasi dan analisis simulasi perbandingan kinerja sinkronisasi carrier pada modulasi M-PSK dan M-QAM menggunakan matlab versi 7.9, maka diperoleh kesimpulan sebagai berikut :

1. Penggunaan costas loop untuk melakukan sinkronisasi carrier pada penerima, saat terjadinya pergeseran fasa, memberikan dampak perbaikan kinerja yang terlihat dari semakin rendahnya nilai BER dari kondisi sebelum menggunakan sinkronisasi carrier . 
2. Hasil pengujian kinerja BER pada modulasi M-PSK sebelum dan sesudah dilakukannya phase recovery menunjukkan perbaikan kinerja sistem sebesar 0,01352 sampai dengan 0,8546 pada rentang Eb/No hingga $30 \mathrm{~dB}$.

3. Hasil pengujian kinerja BER pada modulasi M-QAM sebelum dan sesudah dilakukannya phase recovery menunjukkan perbaikan kinerja sistem sebesar 0,0256 sampai dengan 0,7867 pada rentang Eb/No hingga $30 \mathrm{~dB}$.

\section{DAFTAR RUJ UKAN}

Gibson, Jerry D. (2002). Communication Handbook (2nd edition ed.). India : Rayat Institute of Engineering and Information. Vol.4. No.5, pp : 65-70.

Feigin, Jeff. (2002). Praktis Costas Loop desain (PDF). Dipetik Februari 12, 2014, dari : . http://cunam137.blogspot.com/2013/03/modulasi-digital-costas-loop

Baharudin. (2007). Sinkronisasi Carrier. Dipetik Maret 23, 2014, dari : http://id. wikipedia.org/wiki/sinkronisasicarrier.

Aries, Prastiarso. (2009). Teknik Modulasi Digital. Surabaya : Politeknik Elektronika Negeri Surabaya. Institut Teknologi Sepuluh Nopember Surabaya.

Aryanta, Dwi. (2014). Bahan kuliah Siskom II Costas Loop. Bandung: Institut Teknologi Nasional Bandung. 